\title{
Perancangan Aplikasi Antrian Pada Puskesmas Paal Lima Kota Jambi
}

\author{
$\underline{\text { Jades Purwanto Simarmata }^{1}, \text { Akwan Sunoto }^{2}, \text { Hendrawan }^{3}}$ \\ Teknik Informatika, Fakultas Ilmu Komputer, Universitas Dinamika Bangsa ${ }^{1,3}$ \\ Sistem Informasi, Fakultas Ilmu Komputer, Universitas Dinamika Bangsa ${ }^{2}$ \\ Jl.Jenderal Sudirman Thehok, Jambi, Indonesia \\ E-mail:Jadespurwanto7@gmail.com ${ }^{1}$,akwan@stikom-db.ac.id ${ }^{2}$,hendawan@stikom-db.ac.id ${ }^{3}$
}

\begin{abstract}
The process of queuing of patients at PUSKESMAS Paal Lima Kota Jambi is still done with conventional models. With the level of visit is quite high sometimes the patient until waiting outside the waiting room so that there are patients who do not hear when the name is called, causing the name is passed and does not know the sequence number that has been called. For that, it is necessary to build the queue application so that the service and patient satisfaction in the queue process can be improved. The design of this application uses a waterfall model in which the model starts from the level of need analysis, system design, implementation and unit, and system testing. This research generates a queue application so that with this application, the problem of queues in conventional systems can be solved so that the queue process runs better.
\end{abstract}

Keywords : Queue Application, Puskesmas Paal Lima

\begin{abstract}
Abstrak
Proses antrian pasien pada PUSKESMAS Paal Lima Kota Jambi masih dilakukan dengan model konvensional. Dengan Tingkat kunjungan yang cukup tinggi kadangkala pasien sampai menunggu diluar ruang tunggu sehingga ada pasien yang tidak mendengar ketika namanya di panggil sehingga menyebabkan namanya dilewatkan serta tidak mengetahui nomor urutan yang telah dipanggil. Untuk itu perlu dibangun aplikasi antrian agar pelayanan dan kepuasan pasien pada proses antrian dapat ditingkatkan. Perancangan aplikasi ini menggunakan model waterfall dimana dalam model ini dimulai dari tahap analisis kebutuhan, desain sistem, implementasi dan pengujian unit serta pengujian sistem. Penelitian ini menghasilkan sebuah aplikasi antrian sehingga dengan adanya aplikasi ini maka permasalahan antrian pada sistem konvensional dapat di atasi sehingga proses antrian berjalan lebih baik.
\end{abstract}

Kata Kunci : Aplikasi Antrian, Puskesmas Paal Lima

\section{Pendahuluan}

Kepuasan konsumen merupakan hal yang sangat penting, sehingga peningkatan kualitas terhadap pelayanan konsumen harus terus dilakukan, sistem antrian yang baik akan berpengaruh terhadap perilaku dan kepuasan konsumen. Umumnya antrian terbentuk jika banyaknya pelanggan yang akan dilayani melebihi kapasitas yang tersedia, sehingga menyebabkan para pelanggan yang datang tidak bisa langsung untuk dilayani[1]. Salah satu cara untuk meningkatkan layanan kepada konsumen adalah dengan membangun aplikasi antrian.

Aplikasi antrian merupakan sebuah aplikasi yang dapat membantu meningkatkan kualitas layanan kepada masyarakat untuk menghindari terjadinya desak-desakkan ketika proses antrian dalam mendapatkan layanan[2]. Aplikasi antrian bertujuan agar proses layanan kepada masyarakat dapat berjalan dengan optimal dan berjalan tertib sesuai dengan urutan antrian yang telah ditetapkan.

Antrian merupakan sesuatu hal yang tidak dapat dipisahkan dalam kehidupan sehari-hari, hampir semua pelayanan akan membentuk antrian.Antrian adalah suatu keadaan sistem pelayanan dimana kedatangan waktu pelanggan lebih besar daripada waktu pelayanan[3]. Antrian merupakan suatu keadaan di mana seorang harus menunggu gilirannya untuk mendapatkan pelayanan[4]. Konsep antrian yang sering digunakan adalah konsep antrian FIFO (First In First Out) yaitu antrian yang masuk pertama akan dilayani terlebih dahulu dan begitu seterusnya[5]. 
Waktu tunggu antrian pada sistem konvensional sangat berpengaruh pada tingkat kepuasan pelayanan pasien[6]. Antrian manual cenderung menimbulkan ketidaknyamanan bagi calon pasien yang akan berobat dan oleh karena itu, perli dibuat sebuah rancangan dan implementasi dari suatu system antrian yang membantu antrian untuk menjadi terorganisir dan menyenangkan[7].

Panjangnya antrian serta lamanya waktu tunggu menyebabkan nasabah menjadi bosan dan menganggap waktu mereka terbuang percuma saat mengantri, sementara di luar sana mungkin mereka bisa melakukan sesuatu yang lebih bermanfaat daripada hanya sekedar mengantri. Nasabah mungkin akan membatalkan transaksi di bank tersebut dan memilih melakukan transaksi di bank lain yang memberikan pelayanan lebih memuaskan[8]. Kurang optimalnya pelayanan pada antrian menyebabkan konsumen merasa kurang nyaman [9].

Masalah antrian dapat diatasi dengan menggunakan komputer sehingga dapat membantu perusahan dalam melayani nasabah. Penggunaan aplikasi antrian ini diharapkan agar nasabah tidak perlu lagi membuat barisan panjang untuk mendapatkan pelayanan. Aplikasi antrian akan menghasilkan pelayanan yang baik dan nasabah dapat mengantri dengan tertib[10].

Permasalahan antrian juga terjadi pada Puskesmas Paal Lima yang terletak di Jalan Kolonel M. Kukuh No.38 RT 07. Kelurahan Paal Lima Kota Jambi. Tingkat kunjungan pasien ke puskesmas ini cukup tinggi sehingga kadangkala pasien sampai menunggu diluar ruang tunggu sehingga pasien ada yang tidak mendengar namanya di panggil lalu menyebabkan namanya dilewatkan. Kendala lainnya yang muncul adalah pasien tidak tahu nomor urutan pasien yang sudah dipanggil.

Untuk mengatasi permasalahan tersebut maka perlu dibangun aplikasi antrian pada PUSKEMSAS Pall Lima Kota Jambi sehingga proses pelayanan antrian kepada pasien dapat ditingkatkan.

\section{Metodologi}

Metode penelitian disusun agar kegiatan penelitian lebih terarah, adanpun metode yang digunakan dalam penelitian ini adalah metode deskriptif analisis yaitu dengan cara mengumpulkan data, menganalisa data, membuat suatu pemecahan masalah,dan kemudian disusun untuk menarik kesimpulan mengenai masalah tesebut. Dalam penelitian ini penulis melakukan langkah-langkah sebagai berikut:

1. Studi Pendahuluan

Studi pendahuluan ini merupakan awal dari kegiatan penelitian yang bertujuan untuk mengidentifikasi dan merumuskan masalah-masalah yang terjadi pada proses antrian pada PUSKESMAS Paal Lima Kota Jambi serta mencari masukan-masukan yang diperlukan untuk merancang dan membangun aplikasi antrian

2. Studi literatur

Studi literatur ini dilakukan untuk mencari literatur-literatur yang berkaitan dengan tema penelitian baik itu dari buku maupun penelitian-penelitian terdahulu sehingga dalam pembangunan aplikasi antrian ini penulis memiliki referensi-referensi yang baik.

3. Pengumpulan data

Pengumpulan data pada penelitian ini dilakukan melalui beberapa cara, yang pertama melalui observasi atau pengamatan langsung pada proses antrian, yang kedua melalui wawancara dan yang terakhir mengumpulkan dokumen-dokumen yang berkaitan dengan proses antrian.

4. Analisa Kebutuhan sistem

Analisa kebutuhan sistem ini penulis lakukan dengan mempelajari dan menganalisa dokumen-dokumen yang telah di kumpulkan serta proses yang sedang berlangsung.

5. Desain Sistem.

Pada tahap desain sistem ini hal pertama yang dilakukan melakukan pemodelan terhadap sistem dengan dengan menggunakan use case diagram, activity diagram serta class diagram. Setelah itu dilanjutkan dengan desain input dan output lalu serta pembangunan aplikasi dengan menggunakan bahasa pemrograman php dan mengguanan DBMS MySql. 


\section{Hasil dan Pembahasan}

\subsection{Analisis Sistem yang sedang berjalan}

Proses antrian pasien berobat pada PUSKESMAS Paal Lima Kota Jambi masih dilakukan metode konvensional, dimana prosesnya dapat dijabarkan sebagai berikut:

1. Pasien datang ke puskesmas kemudian menuju meja administrasi

2. Petugas mengarahkan pasien untuk segera mengambil kartu antrian

3. Pasien mengambil kartu antrian yang terletak dimeja administrasi

4. Petugas menghimbau pasien berdasarkan nomor urut

5. Pasien yang nomor urutnya dihimbau segera menuju sumber suara

6. Pasien mengembalikan nomor kartu antrian

7. Petugas cek nomor kesesuaian kartu antrian dengan nomor yang dihimbau

8. Pada periode tertentu petugas merekap laporan, jumlah pasien yang berkunjung ke puskesmas berdasarkan jumlah antrian di tiap harinya.

Berdasarkan penajabaran diatas makadisusun flowchart document yang disebut juga bagan alir formulir (form formulir) atau paperworkyang menunjukan arus laporan dan formulir berikut ini :

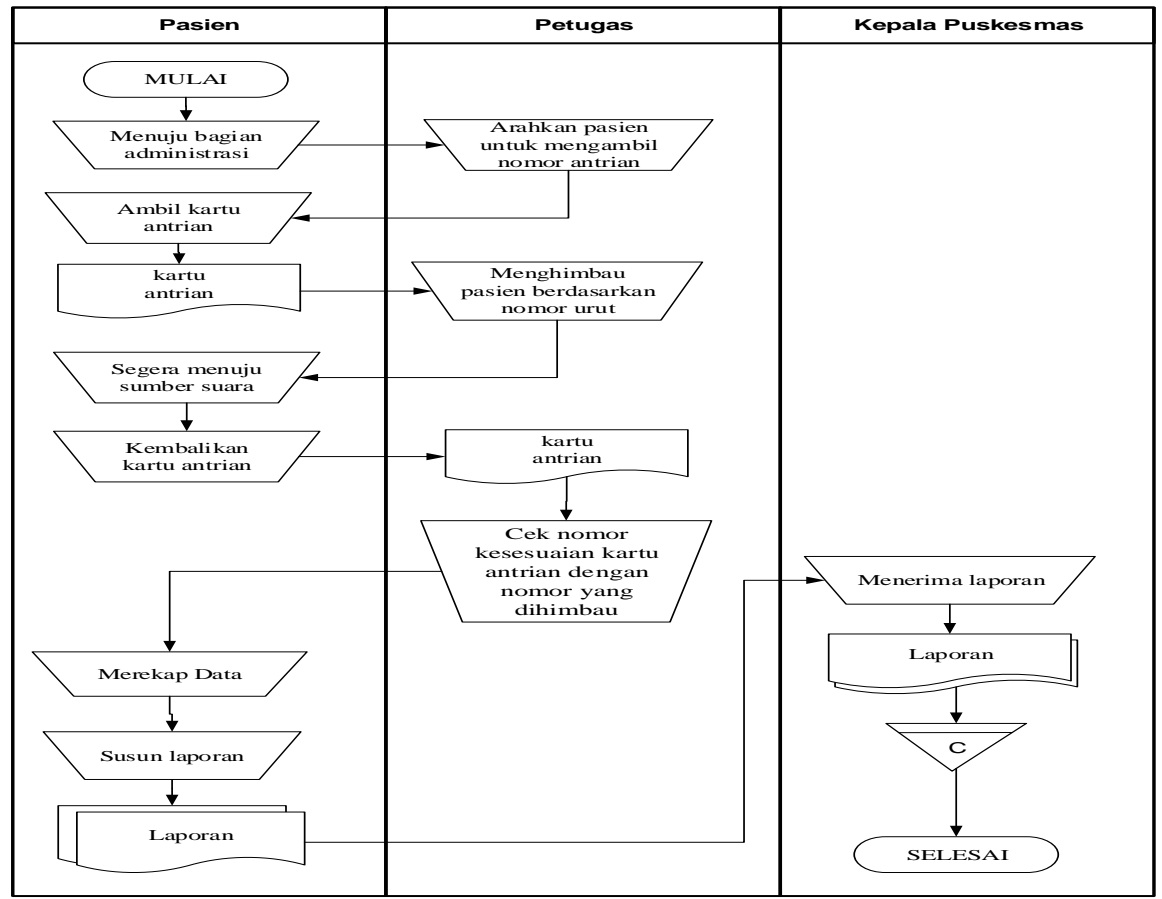

Gambar 1. Bagan Alir Dokumen Antrian

Permasalah yang muncul pada sistem saat ini adalah:

1. Nomor antrian kerapkali tidak sesuai atau tidak berurutan

2. Mempersulit petugas untuk mengarahkan pasien satu per satu

3. Mempersulit petugas saat menghimbau pasien yang sangat banyak

4. Kerapkali pasien tidak mendengar saat dihimbau petugas sehingga antriannya terlewatkan

Solusi untuk permasalahan di atas yaitu membangun aplikasi antrian yang memiliki fitur sebagai berikut:

1. Aplikaski menampilkan nomor antrian pada masing-masing loket pada layar monitor sehingga masingmasing pasien dapat melihat dan memantau langsung antrian yang sedang berjalan

2. Melengkapi aplikasi antrian dengan pengeras suara sehingga pemanggilan antrian akan lebih jelas dan sesuai dengan antrian dari masing-masing loket.

\subsection{Diagram Usecase}

Use case diagram merupakan diagram digunakakan untuk menggambarkan dan menjelaskan tentang bagaimana cara kerja dari sistem yang akan dibangun dilihat dari sudut pandang.objek sebagai pengguna 
system. Pada use case ini juga dijelaskan kegiatan-kegiatan yang dilakukan oleh aktor sebagai penggunanya.

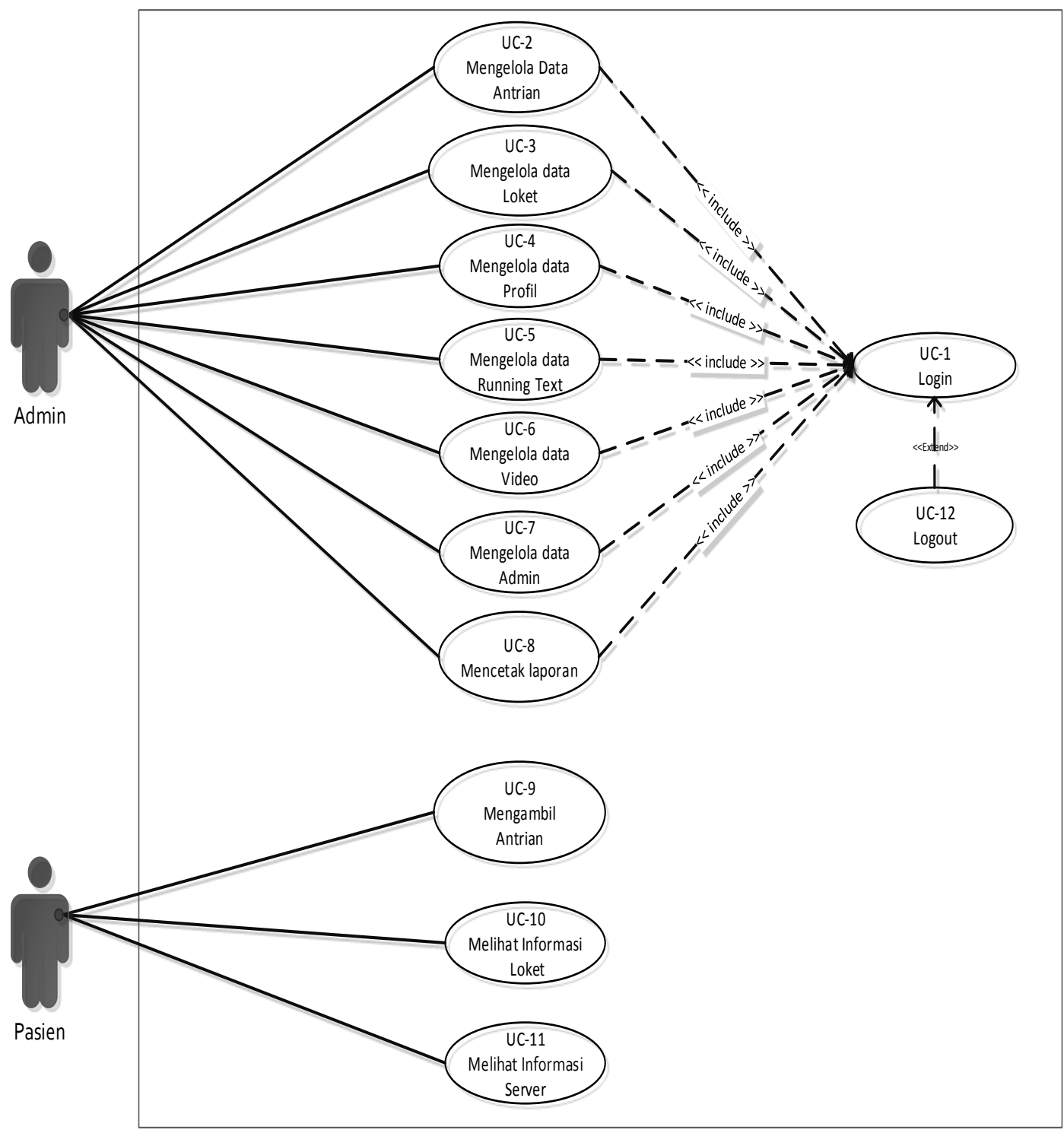

Gambar 2. Diagram UseCase

Pada Use Case ini terdapat dua aktor yaitu admin dan pasien. Admin dapat mengelola data antrian, data loket, profil, runing text, video, serta mencetak laporan. Sedangkan pasien interaksi yaitu mengambil antrian, melihat informasi loket dan meliha informasi yang ditampilkan oleh server.

\subsection{Class Diagram}

Diagram kelas atau class diagram menggambarkan struktur sistem dari segi pendefinisian kelas-kelas yang akan dibuat untuk membangun sistem". Class Diagram(diagram kelas) merupakan diagram paling umum dipakai di semua pemodelan berorientasi objek. Berikut adalah analisis data untuk menggambarkan class diagram pada gambar 4 : 


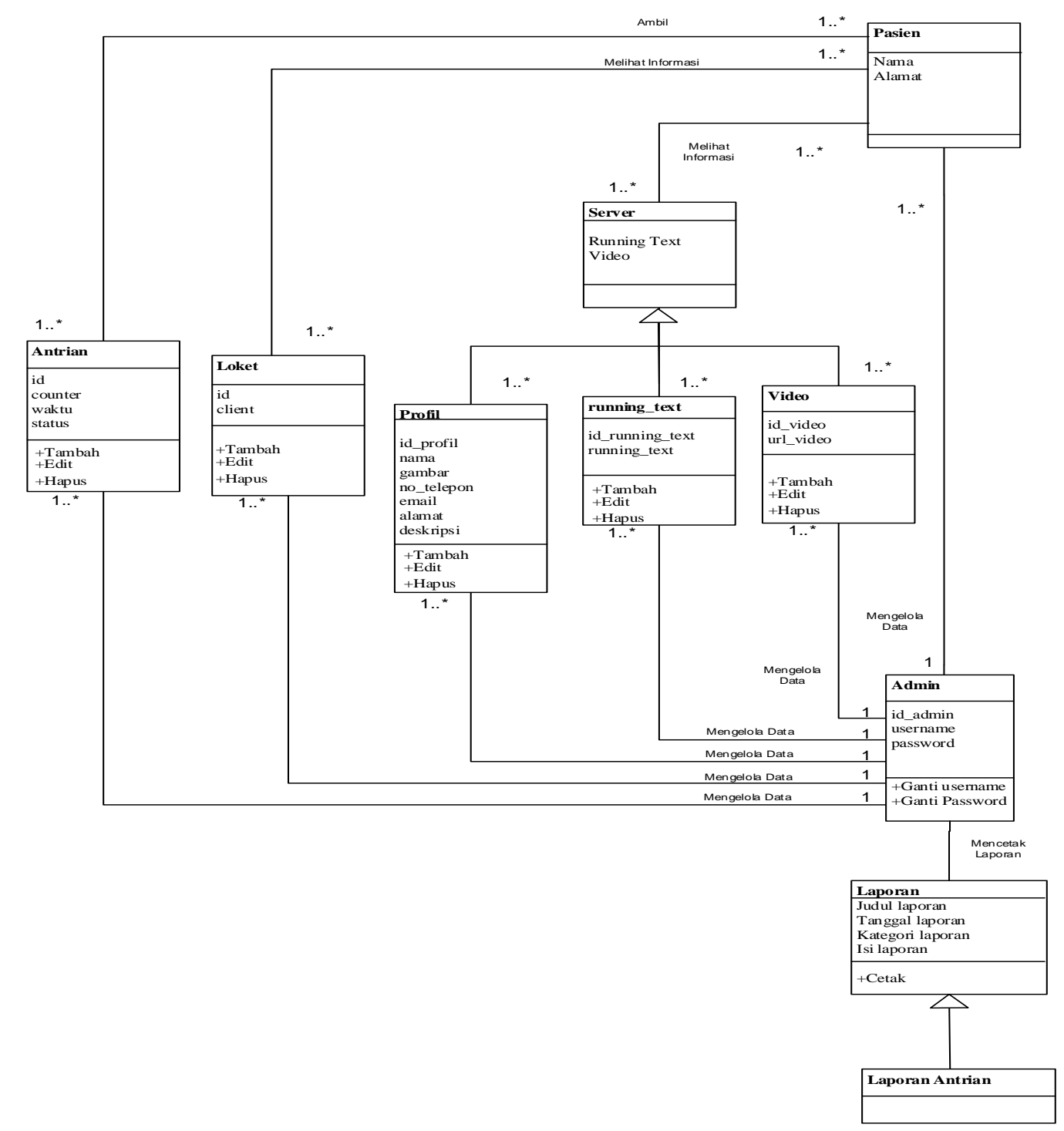

Gambar 3. Class Diagram

\subsection{Hasil Implementasi}

Implementasi adalah tahapan menerjemahkan rancangan kedalam aplikasi dengan mengunakan bahasa pemograman. Dalam rancangan pemograman yang digunakan yaitu PHP serta menggunakan DBMS MySQL.

\section{Form Login}

Tampilan Form InputLogin digunakan pada saat pertama kali user menjalankan aplikasi, maka yang pertama kali akan tampil adalah Halaman Menu Login. Pertama-tama user harus memasukan Username dan Password terlebih dahulu. Halaman Menu Login digunakan untuk menampilkan menumenu di dalam program. 


\section{Form Login}

Username :

admin

Password:

n....

\section{Cancel Login}

Gambar 4. Tampilan Login

2. Menu Utama

Menu utama merupakan halaman yang digunakan oleh admin untuk mengelola menu-menu yang ada di aplikasi seperti menu admin, tampilan home, mengelola menu master maupun mencetak laporan. Dengan adanya menu ini admin dapat mengelola semua tampilan di aplikasi, admin dapat masuk menu utama setelah melalui otentifikasi melalui laman login.

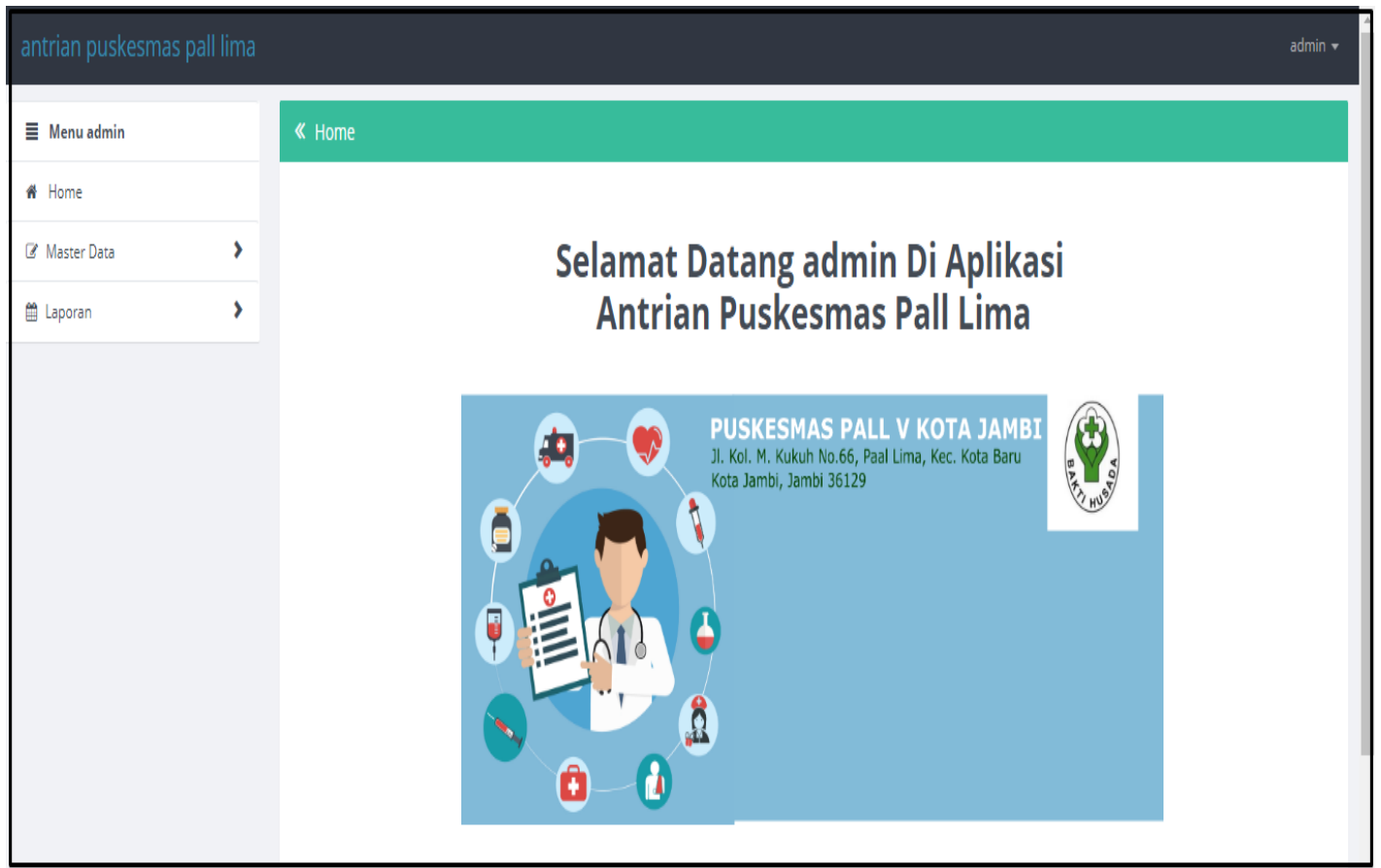

Gambar 5. Tampilan Menu Utama

3. Menu Antrian

Menu antrian digunakan untuk mengelola daftar antrian di masing-masing loket, dimana pada menu ini user dapat mengupdate langsung kondisi antrian dimasing-masing loket sehingga setiap proses pelayanan selesai dilakukan maka antrian berikutnya langsung ditampilkan dan dipanggil melalui aplikasi. 


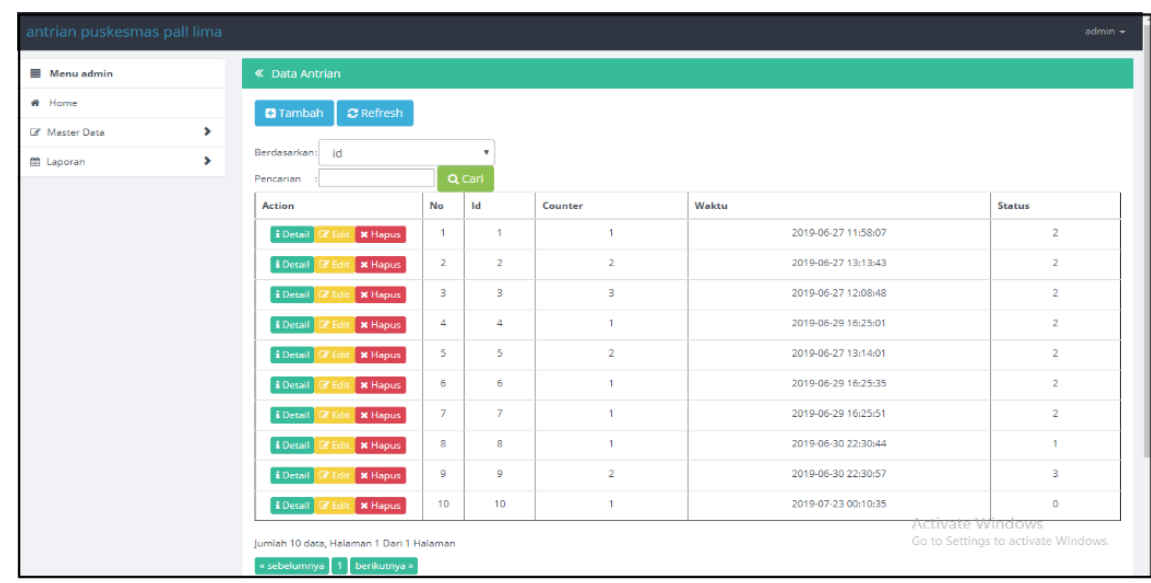

Gambar 6. Tampilan Input Form Menu Antrian

4. Menu Loket

Menu loket digunakan untuk mengelola data loket baik untuk menambahkan, mengedit ataupun menghapus data loket. Dengan adanya menu ini setiap penambahan ataupun perubahan data loket dapat dilakukan dengan cepat.

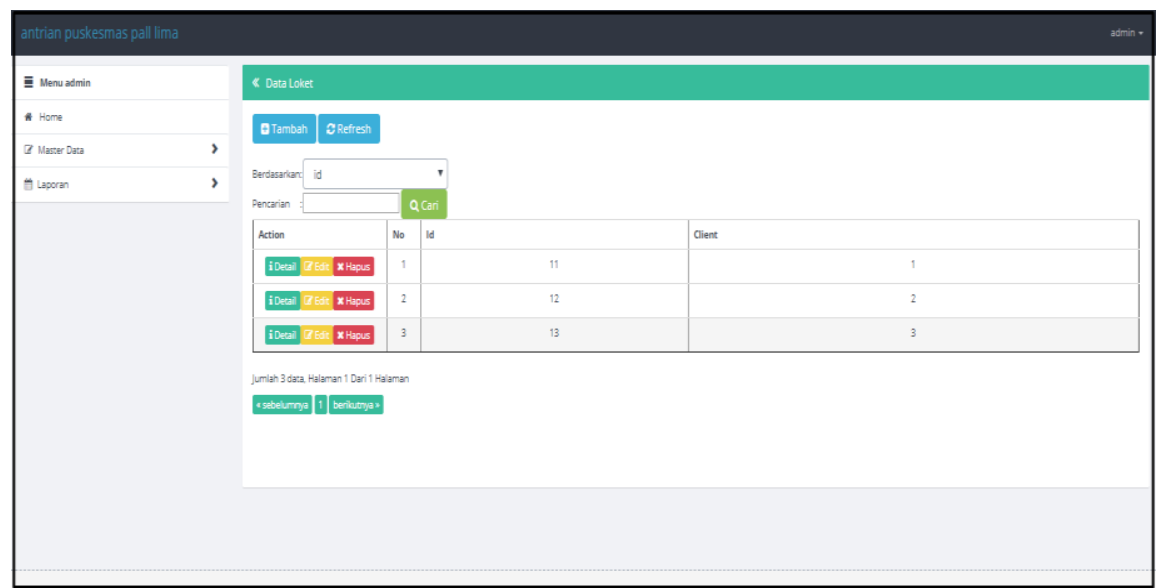

Gambar 7. Tampilan Input Form Menu Loket

5. Menu Running Text

Menu ini digunakan untuk mengatur running text yang muncul dilayar monitor. Dengan adanya menu ini admin bisa mengatur informasi apa saja yang akan ditampilkan sehingga informasi yang ditampilkan selalu uptodate.

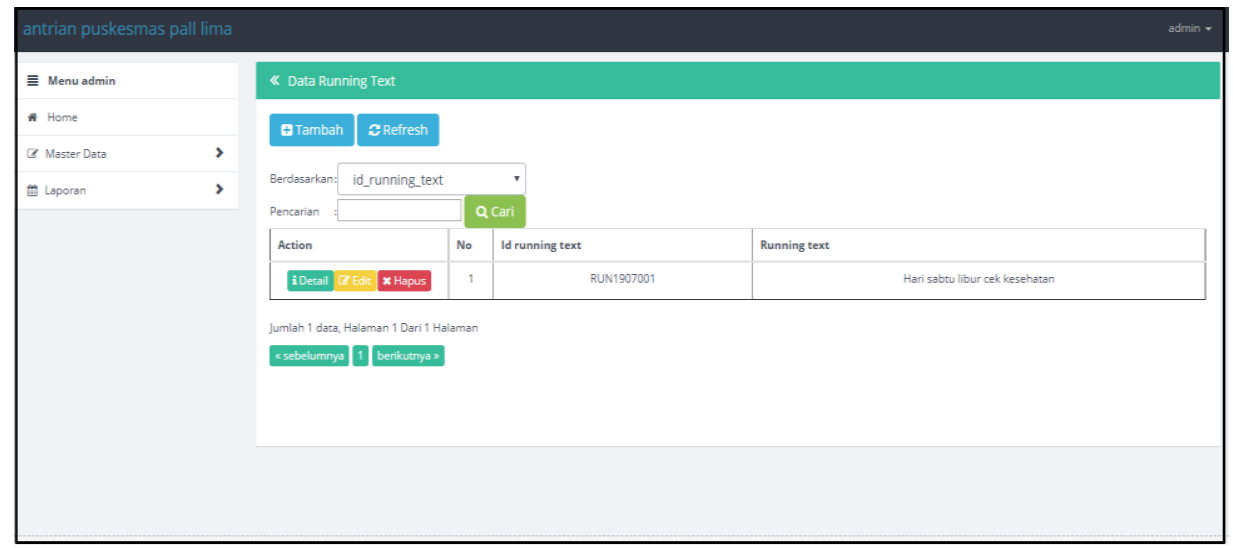

Gambar 8. Tampilan Input Form Menu Running Text 
6. Menu Video

Menu ini digunakan untuk mengatur video yang akan ditampilkan pada layar monitor antrian. Dengan adanya menu ini video yang akan ditampilkan dilayar monitor antrian bisa disesuaikan dengan kebutuhan pihak puskesmas.

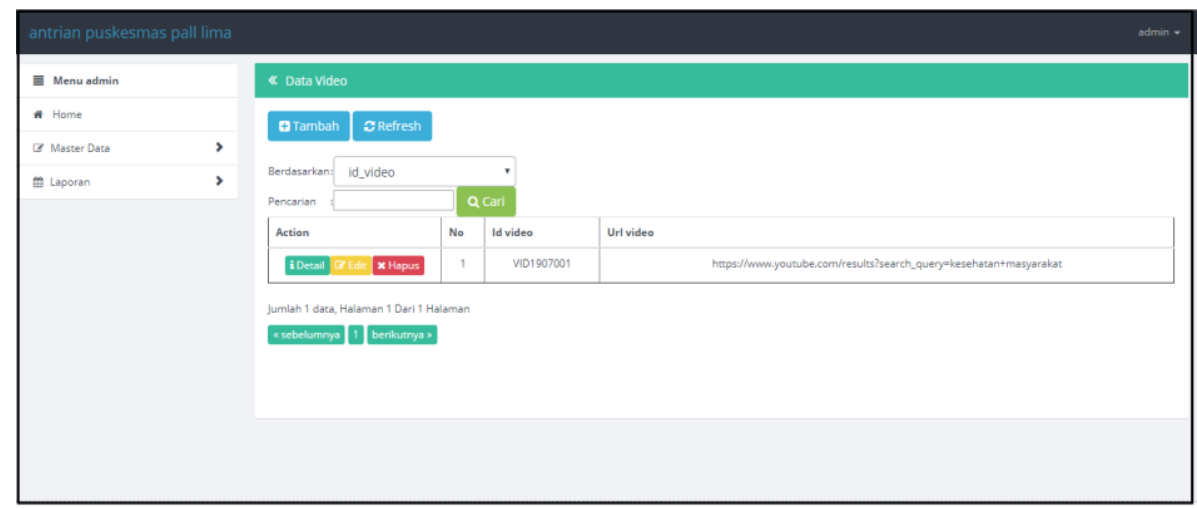

Gambar 9. Tampilan Input Form Menu Video

9. Form pengambilan antrian

Form ini digunakan untuk pengambilan antrian pada masing-masing loket. Pada form antrian ditampilkan posisi nomor urut terakhir pada masing-masing loket sehingga pasien mengetahui kondisi antrian terkini.

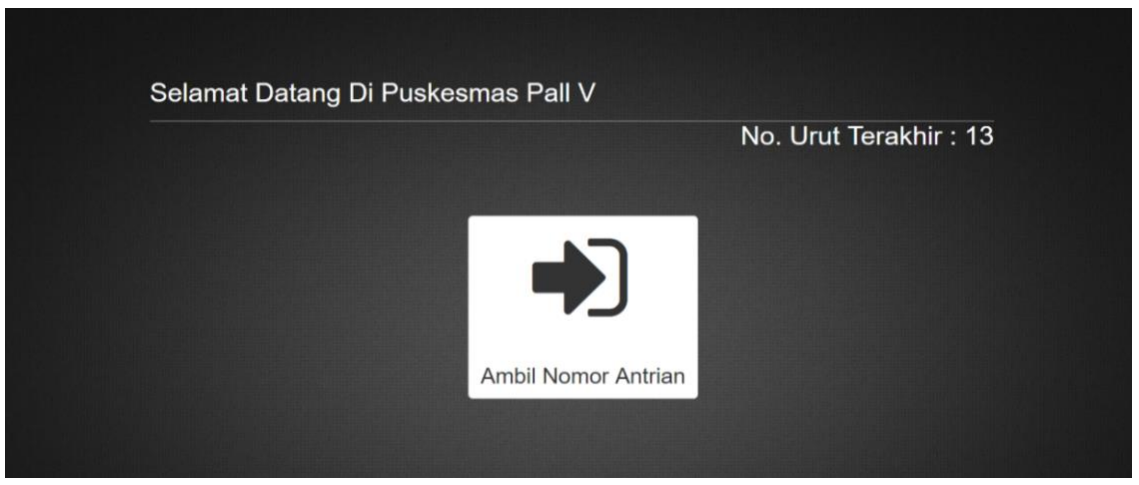

Gambar 10. Form pengambilan antrian

10. Form pemanggilan antrian

Form ini digunakan oleh masing-masing loket untuk menginput dan memanggil antrian pada masing-masing loket sehingga proses pelayanan antrian bisa berjalan lebih optimal :

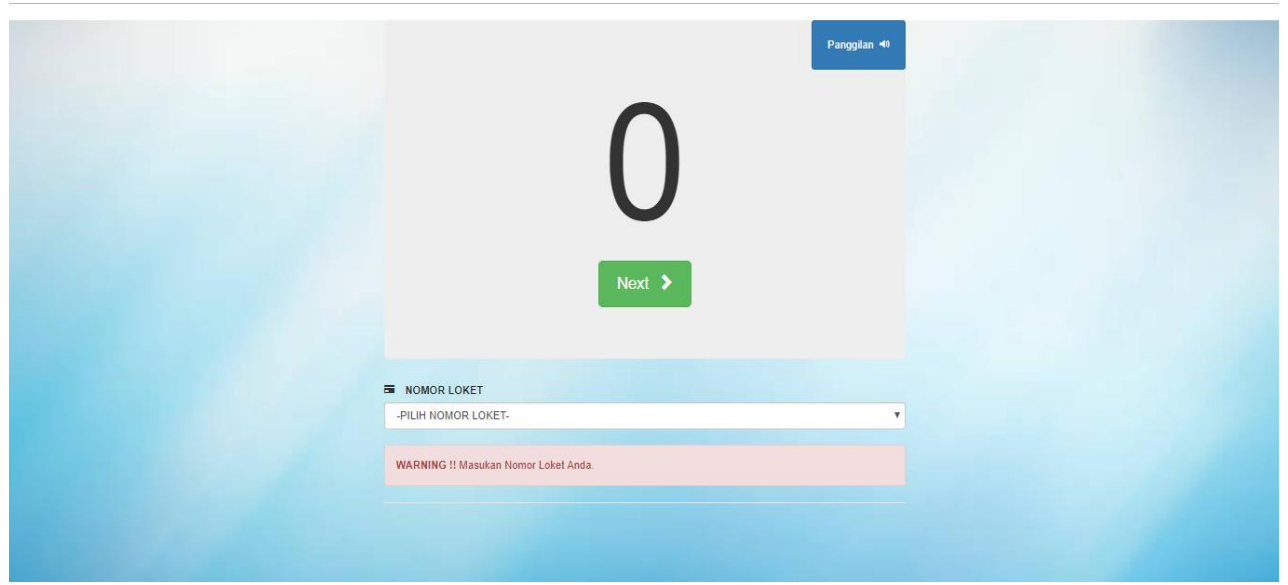

Gambar 11. Tampilan Input Form Loket 
11. Form Server

Form ini menampilkan kondisi antrian dimasing-masing loket. Seperti pada gambar terlihat pada loket 1 nomor antrian 7, pada loket 2 nomor antrian 5 dan pada loket 3 nomor antrian 3. Sehingga posisi antrian bisa dilihat langsung oleh masing-masing pasien.

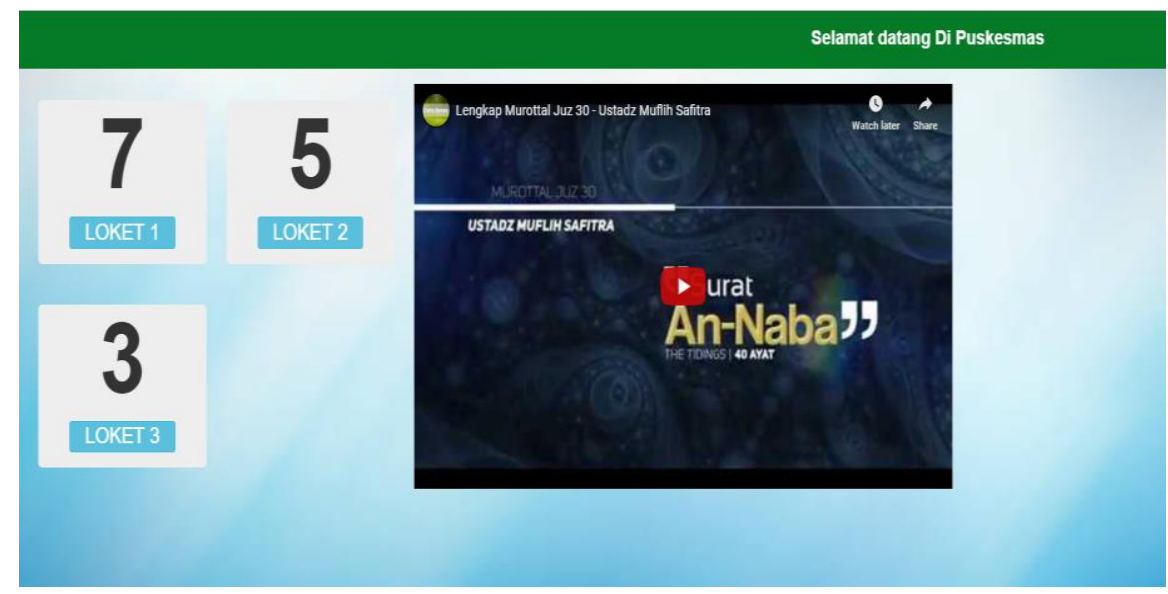

Gambar 12. Tampilan InputForm Server

\subsection{Hasil Pengujian}

Dari hasil pengujian dengan metode Black Box maka dapat dipastikan bahwa aplikasi yang dibuat telah sesuai dengan desainnya dan dapat dipergunakan dengan baik tampa ada kesalahan. Hasil pengujianya dapat dilihat pada tabel berikut.

Tabel 1. Pengujian Halaman Antrian

\begin{tabular}{|c|c|c|c|c|c|c|}
\hline No. & Deskripsi & $\begin{array}{l}\text { Prosedur } \\
\text { Pengujian }\end{array}$ & Masukan & $\begin{array}{c}\text { Keluaran } \\
\text { yang } \\
\text { Diharapkan }\end{array}$ & $\begin{array}{c}\text { Hasil } \\
\text { Pengujian }\end{array}$ & Kesimpulan \\
\hline 1 & $\begin{array}{l}\text { Pengujian pada } \\
\text { menambah data } \\
\text { Antrian }\end{array}$ & $\begin{array}{l}\text { - Login } \\
\text { - Mengklik } \\
\text { menu Antrian } \\
\text { - Klik tombol } \\
\text { tambah }\end{array}$ & $\begin{array}{l}\text { - Mengisi data } \\
\text { - Klik simpan }\end{array}$ & $\begin{array}{l}\text { Data pada } \\
\text { database } \\
\text { bertambah dan } \\
\text { Menampilkan } \\
\text { Pesan bahwa } \\
\text { data berhasil } \\
\text { ditambah }\end{array}$ & Sesuai & Valid \\
\hline 2 & $\begin{array}{l}\text { Pengujian pada } \\
\text { menambah data } \\
\text { Antrian dan data } \\
\text { tidak lengkap }\end{array}$ & $\begin{array}{l}\text { - Login } \\
\text { - Mengklik menu } \\
\text { Antrian } \\
\text { - Klik tombol } \\
\text { tambah }\end{array}$ & $\begin{array}{l}\text { - Mengisi data } \\
\text { - Klik simpan }\end{array}$ & $\begin{array}{l}\text { Menampilkan } \\
\text { Pesan bahwa } \\
\text { data belum } \\
\text { lengkap }\end{array}$ & Sesuai & Valid \\
\hline 3 & $\begin{array}{l}\text { Pengujian pada } \\
\text { mengedit data } \\
\text { Antrian }\end{array}$ & $\begin{array}{l}\text { - Login } \\
\text { - Mengklik menu } \\
\text { Antrian } \\
\text { - Pilih data } \\
\text { - Klik tombol edit }\end{array}$ & $\begin{array}{l}\text { - Mengisi data } \\
\text { - Klik update }\end{array}$ & $\begin{array}{l}\text { Proses edit } \\
\text { Berhasil dan } \\
\text { menampilkan } \\
\text { Pesan bahwa } \\
\text { data berhasil } \\
\text { diedit }\end{array}$ & Sesuai & Valid \\
\hline 4 & $\begin{array}{l}\text { Pengujian pada } \\
\text { menghapus data } \\
\text { Antrian }\end{array}$ & $\begin{array}{l}\text { - Login } \\
\text { - Mengklik } \\
\text { menu } \\
\text { Antrian } \\
\text { - Pilih data } \\
\text { - Klik } \\
\text { tombol } \\
\text { hapus }\end{array}$ & Klik Ok & $\begin{array}{l}\text { Proses hapus } \\
\text { Berhasil dan } \\
\text { Menampilkan } \\
\text { Pesan bahwa } \\
\text { data dihapus }\end{array}$ & Sesuai & Valid \\
\hline
\end{tabular}




\section{Kesimpulan}

Dengan adanya aplikasi antrian maka pelayanan kepada pasien bisa ditingkatkan, melalui aplikasi ini pasien bisa langsung memantau kondisi antrian dimasing-masing loket melalui layar monitor, selain itu di aplikasi sudah dilengkapi langsung dengan suara untuk memanggil nomor antrian sesuai dengan nomor antrian yang tertera dilayar monitor sehingga kemungkinan antrian terlewatkan bisa diminimalkan. Untuk penelitian kedepan bisa dilengkapi dengan pemesanan antrian melalui web atau aplikasi mobile sehingga pasien tidak mesti mengambil antrian langsung di PUSKESMAS.

\section{Daftar Rujukan}

[1] E. W. Fridayanthie, "Sistem Informasi Antrian Konsumen Berbasis Desktop Pada PT Wom Finance Kemayoran Jakarta," vol. 5, no. 2, pp. 99-103, 2017.

[2] M. S. Maulana, "Pengembangan Dan Implementasi Aplikasi Antrian Loket Pelayanan Masyarakat Menggunakan Metode Multi Chanel-Single Phase (Studi Kasus: Disdukcapil Kabupaten Kubu Raya)," J. Khatulistiwa Inform., vol. 4, no. 1, pp. 75-83, 2016

[3] Suparti and Wulandari, "Analisis Antrian Service Motor di DealerResmi Yamaha Kondang Simo Dengan Simulasi Arena”. Jurnal Teknik Industri dan Informasi. Vol. 3, no.1, pp.9-18,2014

[4] S. Bahar, M. L. Mananohas, and C. Montolalu, "Model Sistem Antrian dengan Menggunakan Pola Kedatangan dan Pola Pelayanan Pemohon SIM di Satuan Penyelenggaraan Adminstrasi SIM Resort Kepolisian Manado," d'CARTESIAN, vol. 7, no. 1, p. 15-21, 2018.

[5] E. Widiantono and T. Sukmono, "Analisis Antrian Service Motor di Dealer Resmi Honda," PROZIMA (Productivity, Optim. Manuf. Syst. Eng., vol. 1, no. 2, p. 99-106, 2018.

[6] N. Laeliyah and H. Subekti, "Waktu Tunggu Pelayanan Rawat Jalan dengan Kepuasan Pasien Terhadap Pelayanan di Rawat Jalan RSUD Kabupaten Indramayu," J. Kesehat. Vokasional, vol. 1, no. 2, p. 102-112, 2017.

[7] R. A. Zulfikar and A. A. Supianto, "Rancang Bangun Aplikasi Antrian Poliklinik Berbasis Mobile," J. Teknol. Inf. Dan Ilmu Komputer., vol. 5, no. 3, pp. 361-370, 2018.

[8] B. W. Nia Puspita Sari, Sugito, "Penerapan Teori Antrian Pada Pelayanan Teller Bank X Kantor Cabang Pembantu Puri Sentra Niaga," J. Gaussian, vol. 6, no. 1, pp. 81-90, 2016.

[9] D. Nurfitria, N. Nureni, and I. T. Utami, "Analisis Antrian Dengan Model Single Channel Single Phase Service Pada Stasiun Pengisian Bahan Bakar Umum (Spbu) I Gusti Ngurahrai Palu," J. Ilm. Mat. Dan Terap., vol. 12, no. 2, pp. 65-71, 2017.

[10] Saputra Teguh, B. Irawan, and Ilhamsyah, "Aplikasi Antrian Nasabah Bank Menggunakan Teks Dan Suara Berbasis Jaringan Wireless Lokal Area Network (WLAN)," J. Coding Sist. Komput. Univ. Tanjungpura, vol. 02, no. 2, pp. 1-7, 2014. 